\title{
Museología subalterna (sobre las ruinas de Moctezuma II)
}

\author{
por \\ Luis Gerardo Morales Moreno ${ }^{1}$ \\ Universidad Autónoma del Estado de Morelos \\ Escuela Nacional de Conservación, Restauración y Museografía, INAH \\ México
}

«Museología subalterna» combina la mirada del historiador con el espacio de las observaciones museográficas o expográficas con el propósito de acercar al lector a una síntesis sobre los museos de México. Hacemos una museología histórica porque intentamos una «historización» de las diferentes modernidadesde la sociabilidad y la mirada públicas en territorios extra-europeos. Optamos por un posicionamiento crítico con relación a las hegemonías europeas que produjeron la invención de la observación museográfica con una cauda diversificada de diseños, arquitecturas, tecnologías e ideas sociales y educativas. De esta manera, comprendemos el museo como un espacio de la diferencia y la representación, que hace posible una concepción genealógica de la discontinuidad. La transferencia europea de la cultura de los museos en América no fue una mera reproducción, sino que recreó modalidades y prácticas genuinas. Por esto, denominamos nuestro ensayo «museología subalterna» porque hay países postcoloniales con representaciones significativas como la creación de una cultura moderna de la ancestralidad que, en el caso de México, propició la formación de un Estado Nación con una gran legitimidad simbólica.

PALABRAS ClAVE: museología subalterna; diferencia; representación; discontinuidad modernidades diferentes; conciencia inmanente; conciencia trascendente; museopatria.

\section{UMBRAL MUSEOGRÁFICO: EL SITIO DE LA MIRADA}

A la manera de las museografías modernas «representamos» nuestro ensayo con un umbral de un documento resguardado en una vitrina, que es un libro

1 Este trabajo se inscribe en el proyecto de investigación «Museos, memoria y antropología: América y otros espacios de colonización», financiado por el Ministerio de Ciencia e Innovación del Gobierno de España (referencia: HAR2009-10107). 
abierto en alguna página de la Segunda Carta-Relación escrita por Hernán Cortés y dirigida al Emperador Carlos V, un 30 de octubre de 1520, en donde leemos:

En lo del servicio de Mutezuma y de las cosas de admiración que tenía por grandeza y estado, hay tanto que escribir que certifico a vuestra alteza que yo no sé por do comenzar, que pueda acabar de decir alguna parte de ellas. Tenía una casa donde tenía un muy hermoso jardín con ciertos miradores que salían sobre él, y los mármoles y losas de ellos eran de jaspe muy bien obradas. En esta casa tenía diez estanques de agua, donde tenía todos los linajes de aves de agua que en estas partes se hallan, que son muchos y diversos, todas domésticas; y para las aves que se crían en la mar, eran los estanques de agua salada, y para las de ríos, lagunas de agua dulce, la cual agua vaciaban de cierto a cierto tiempo, por la limpieza. Había para tener cargo de estas aves trescientos hombres, que en ninguna otra cosa entendían. Había otros hombres que solamente entendían en curar las aves que adolecían. Sobre cada alberca y estanques de estas aves había sus corredores y miradores muy gentilmente labrados, donde el dicho Mutezuma se venía a recrear y a las ver. Tenía en esta casa un cuarto en que tenía hombres y mujeres y niños blancos de su nacimiento en el rostro y cuerpo y cabellos y cejas y pestañas. Tenía otra casa muy hermosa donde tenía un gran patio losado de muy gentiles losas, todo él hecho a manera de un juego de ajedrez; y la mitad de cada una de estas casas era cubierta el soterrado de losas y la mitad que quedaba por cubrir tenía encima una red de palo muy bien hecha; y en cada una de estas casas había un ave de rapiña; comenzando de cernícalo hasta águila, todas cuantas se hallan en España, y muchas más raleas que allá no se han visto. Había en esta casa ciertas salas grandes bajas, todas llenas de jaulas grandes de muy gruesos maderos muy bien labrados y encajados, y en todas o en las más había leones, tigres, lobos, zorras, y gatos de diversas maneras. Tenía otra cosa donde tenía muchos hombres y mujeres monstruos, en que había enanos, corcovados y contrahechos, y otros con otras deformidades, y cada una manera de monstruos en su cuarto por sí; y también había para éstos, personas dedicadas para tener cargo de ellos, y las otras casas de placer que tenía en su ciudad dejo de decir, por ser muchas y de muchas calidades.

\section{CÉDUla DE PIE DE OBJETO}

Desde una perspectiva contemporánea, la mirada que funda a la museología histórica mexicana fue la del emperador Moctezuma II [Mutezuma] embebido en la contemplación de sus jardines y casas de pasatiempo con sus numerosas especies de animales y rarezas. La mirada del gentil emperador aparece entretejida con la del conquistador Hernán Cortés quien observa con admiración y extrañeza un Nuevo Mundo. La mirada de Mutezuma escenifica una imagen literaria de la que desprendemos un par de preguntas: ¿cómo comprender la pulsión por admirar colecciones de especímenes y «cosas raras»? ¿Cómo interpretar el gozo íntimo de recolectarlos, guardarlos y observarlos de 
manera privada? En la interpretación dominante de la Modernidad que inventa el «descubrimiento de América» como una ruptura con la Edad Media, los objetos «salvajes» representan fantasmas de poderío mientras que los occidentales operan como muestras de eficiencia técnica. En ambos, el fetichismo encubre el «primer mestizaje» de las miradas por los objetos que representan el mito de poderío de los «salvajes» (Mutezuma) y el mito de origen de los civilizados (Cortés). Durante el siglo XIX, el romanticismo patriótico mexicano retoma la «mirada de Mutezuma» para fundar allí la preexistencia de la Nación renacentista.

Esta investigación incorpora el enigma de esa «mirada mestiza fundante» para explorar la «modernidad museográfica subalterna», a partir de los conceptos occidentales que conciben el museo como regulación racional de las ópticas estética y descriptiva del mundo. La regulación racional produce los campos de visión y, en ellos, despierta la ambición por la posesión del mundo. Desde ahí, desatan la «larga duración» de la organización y exhibición sistemática de las «cosas» de la memoria pública. La mirada de Mutezuma abreva en el cruzamiento de miradas, silencios y signos entre dos civilizaciones diferentes, ahí se conserva el secreto del intenso placer de los ojos curiosos con sus objetos imaginarios. La situación política y económica actual de México ofrece un momento privilegiado para el análisis del pasado reciente, entendido como crítica de las imágenes fundantes. Se nos plantea un dilema: ¿Estamos ante un horizonte posnacionalista posrevolucionario, o solo hay que despojarnos de las anteojeras que impuso la modernidad revolucionaria?2 Cualquier respuesta a ambas preguntas exige una reubicación del sitio histórico de nuestra mirada ${ }^{3}$.

\section{DIFERENTES OPCIONES DE VISITA, DIFERENTES MODERNIDADES}

«Museología subalterna» combina la mirada del historiador con el espacio de las observaciones museográficas o expográficas con el propósito de acercar al lector a una síntesis sobre los museos de México. También hacemos una museología histórica porque propiciamos una «historización» de las diferentes

2 Al respecto, véase Guillermo Zermeño, 2002: 41-146. Entre otras tesis, el autor afirma: «el nacionalismo solo se entiende si se observan los usos que la modernidad ha hecho del pasado»: 67.

3 Véase el ensayo de Tostado, 2003: 18-22. Tostado propone una hipótesis polémica, la supuesta desaparición de la política cultural en el México contemporáneo. Para una perspectiva más amplia, véase Grüner, 2001. 
modernidades de la sociabilidad y la mirada públicas en territorios extra-europeos. La condición subalterna opta por un posicionamiento crítico con relación a las hegemonías europeas que produjeron la invención de la observación museográfica con una cauda diversificada de diseños, arquitecturas, tecnologías e ideas del pensamiento social y educativo. De esta manera, buscamos la comprensión del museo como espacio de la diferencia y la representación, que hace posible una concepción genealógica de la discontinuidad. La transferencia europea de la cultura de los museos en América no fue una mera reproducción, sino que recreó modalidades y prácticas genuinas. Por esto, optamos por denominar nuestro ensayo «museología subalterna» porque hay países postcoloniales con representaciones significativas como la creación de una cultura moderna de la ancestralidad que, en el caso de México, ha permitido mantener durante el siglo XX, un Estado Nación sólido. La «ancestralidad» comprende, sobre todo, las ruinas más antiguas de la era precolombina. Todo ello devino en una memoria histórica que abarca, además, los edificios eclesiásticos del culto católico, como iglesias, ex-conventos o monasterios de la Nueva España, así como inmuebles históricos y artísticos del México Independiente y Republicano. El culto moderno que propician las museografías consiste en subrayar la importancia del cambio histórico.

Los museos del siglo XX en México incorporaron junto a la ancestralidad, la modernidad revolucionaria. Estos gestos plásticos se sumaron a una proliferación de imágenes icónicas «de lo mexicano» sobre todo en la radio, el cine y la televisión, de 1946 en adelante. En la retórica política, la Revolución Mexicana de 1910-1920 se convirtió en la autoconciencia estética que observa como una liberación el reformismo agrario, junto con la emergencia de los grandes sindicatos nacionales de industria, comercio y transportes. Desde nuestro punto de vista, la singularidad del proceso musé́stico mexicano radica en ese proceso de diferenciación y discontinuidad que lo aleja del resto de las repúblicas de América.

Como ya sabemos, el modelo del museum proviene de un paradigma occidental moderno. De acuerdo con esto, la «primera modernidad» arranca con el gabinete ilustrado mediterráneo inmerso en un contexto cortesano y aristocrático que concibe al objeto como parte de una conciencia inmanente. Esto significaba que el conocimiento de las colecciones de objetos abría un campo de observación empírica, donde los hechos de la naturaleza se explicaban por el mejor conocimiento humano de la misma. Se crea así la categoría de los objetos curiosos porque son susceptibles de cuestionamiento e indagación científica. Esta vertiente desemboca hasta fines del siglo XX, con la intención de convertir a la museología, inclusive, en una disciplina científica. La «otra modernidad» coloca al objeto museográfico dentro de la esfera de los fenómenos 
maravillosos. Como los objetos maravillosos encierran, posiblemente, las claves del hermético código de lo Divino, entonces no únicamente constituyen materia observable. Sino que pertenecen a una conciencia trascendental que encuentra en los objetos museográficos determinados símbolos. El objeto no es solo un objeto, trasciende como una metáfora del mundo.

En México, el nacionalismo patriótico además de establecer los fundamentos científicos del Origen común de los mexicanos, prolongó también la conciencia trascendental hasta los años 1982-1987 cuando todavía se otorgaron generosos fondos públicos para la creación del Museo Nacional de las Intervenciones, el Museo Nacional de Arte y el Museo de Templo Mayor. En sus museos arqueológicos, históricos y etnográficos, sobre todo, la sociedad mexicana aparece envuelta entre dos modernidades. Por un lado, la conciencia moderna queda representada por una cultura de la resistencia a las dominaciones extranjeras así como por la autoconciencia estética —el muralismo del siglo XX; y, por el otro, aparece la consagración indigenista del pasado precolombino, como una reafirmación del criollismo novohispano del siglo XVIII. Bajo estas premisas, emergen desde 1986 los llamados museos comunitarios de Oaxaca que son predominantemente de raíz zapoteca y mixteca. En la tradición de la memoria museográfica mexicana los indios vivos quedaban fuera del escenario político, solo cabían como objetos muertos, reliquias, tesoros y pinturas mas no como actores de su destino. En la memoria reconstruida desde el escaparate de la nación cabían el estandarte guadalupano del cura insurgente Miguel Hidalgo, o la cama del presidente Benito Juárez, el presidente-indio (muerto en 1872) solo en su condición de moderno, lo mismo que la prohibición de los claustros y la conversión de los bienes de la iglesia en monumentos históricos (desde 1859-1862). La visibilidad y la invisibilidad se ofrecen como los dos ángulos de la observación museográfica donde lo que observamos como un testimonio o evidencia histórica, en la ritualidad del espacio y su narrativa expositiva, puede transformarse en la metafísica de la razón moderna mexicana ${ }^{4}$. El liberalismo ontológico funda en el indigenismo, más que en el hispanismo, y en el mestizaje republicano su propio paradigma: los museos debían servir para la transmisión de la verdad objetiva de la nación.

El Benito Juárez de la historia moderna no resulta recuperable tanto por sus raíces indígenas, como por la cantidad de tinta que empleó para inventar una nación diferente a la de la antigüedad azteca o la época novohispana. La imagen más recurrente que tenemos en mente es la «del Juárez», abogado y

4 Véase la crítica de la modernidad unilateral de los liberales con su metafísica trascendental, en O'Gorman, 1977. 
presidente, yendo a la frontera norte con los Estados Unidos cargado de papeles, «con la república bajo el brazo», huyendo de la persecución conservadora y los invasores franceses 5 . Por la iconografía producida sobre todo durante el siglo XX, sabemos que don Benito no era carismático. Sin embargo, con ese rostro impasible multiplicado en miles de retratos, monumentos y bustos, Juárez ha encarnado - para escritores, pintores, periodistas, historiadores, abogados, militares, políticos y millones de mexicanos - la imagen emblemática del ingreso de México a la modernidad. Una modernidad política y económica que recreó, en la museografía porfirista, desde 1887, la tradición del culto a los ancestros aztecas y al propio Juárez ${ }^{6}$. Esa tradición ritual tejió, de manera persistente, el hilo de la nueva nación e hizo de Juárez un símbolo de unidad, más que de ruptura.

El presidente de origen zapoteco, vestido con su levita negra y empuñando las Leyes de Reforma (nacionalización de los bienes eclesiásticos en 1859), magnifica la presencia del pasado de un modo problemático. ¿Qué hacer con la herencia de la Nueva España, con su legislación corporativa y una iglesia que regulaba las imágenes y prácticas del culto católico sin tolerancia de ningún otro? ¿Cuál debía ser el México del futuro? La figura de Juárez representa la recuperación de la soberanía conquistada por los héroes Miguel Hidalgo, José María Morelos y Vicente Guerrero durante las guerras insurgentes de 1810 y 1821 . El liberalismo constitucionalista de 1857, junto con las Leyes de Reforma de 1859, marcaron para siempre el destino del México moderno identificado ya no con las corporaciones, sino con los ciudadanos.

\section{SALA DE EXPOSICIONES TEMPORALES: LA ENSEÑANZA OBJETIVA}

Generalmente, cuando se aborda el tema de los museos parece que estamos ante una institución y un concepto familiares. Sin embargo, resulta indispensable precisar sobre qué tipo de museos estamos hablando, porque el contexto de referencia de los objetos museográficos cambia de una sociedad a otra. La historia de los museos de México atañe, de manera medular, a los aproximadamente 115 recintos que dependen del Instituto Nacional de Antropología e Historia (INAH), aunque abarca también otras instituciones fundamentales de la política cultural mexicana, como el Instituto Nacional de Bellas Artes (INBA) con otras 16 dependencias. Su tradición museográfica (discursiva y

5 Una propuesta didáctica de la vida de Juárez, para niños, según la versión de su esposa, Margarita Maza, véase Bur, 2005.

6 Véase Morales, 1991: 398-411. Morales, 1994. 
expositiva), proviene de una comunidad científica e intelectual, que desde fines del siglo XIX utilizó al viejo Museo Nacional (fundado en 1825-1831) para el «despliegue representacional» de saberes empíricos, donde la observación directa de las cosas desempeñó un papel central ${ }^{7}$. Durante más de un siglo, se postuló que la mirada del observador no intervenía en la construcción del objeto museográfico. La ausencia del observador creaba un nuevo lugar: la neutralidad del museo con un observador-visitante de ojo sin cuerpo. De hecho, en las modernidades europeas o extra-europeas, imperiales o coloniales, el museo se distingue porque escinde al sujeto de sus obras, y al objeto museográfico de su contexto original ${ }^{8}$. Muchos museos parten todavía del supuesto de que una exhibición ideal funciona como espejo, porque su imagen resulta identificada con su objeto. Cuando historiamos el objeto de la imagen representada nos damos cuenta de que en distintos periodos históricos las museografías no siempre funcionaron como espejos de identidad colectiva, sino también como imágenes que representaban deseos e intereses de determinados grupos sociales y comunidades intelectuales. Mediante «presentificaciones» del pasado 9 , el museo fabrica sentido. Hace inteligible lo que de hecho aparece de forma inconexa, dispersa, o desconocida. Los objetos-evidencia constituyen fragmentos materiales de un pasado ya ido, en cuya ausencia el museo de la racionalidad moderna organizó una enciclopedia de ilustraciones. En los museos arqueológicos e históricos prevaleció la lectura cronológica y lineal de los conceptos civilización, barbarie, cultura y progreso. Con ellos se implantó el paradigma museográfico ilustrado de la «enseñanza objetiva».

Es así que buscamos la comprensión del espacio museístico como un espacio de la diferencia y la representación, y por lo tanto como una heterotopía que hace posible una concepción genealógica de la discontinuidad. Esto nos permite concebir el museo como una construcción para el progreso que avanza por su crítica de las nociones ilustradas del propio progreso y la libertad, así como del nacionalismo revolucionario. Esa recuperación progresiva de una visión crítica de la Ilustración y la Revolución es lo que hace posible la acepción de un museo de la posmodernidad. Una posmodernidad que se aleje de las ideas totalizantes y controladoras de la razón y el saber unánimes, homogéneos, imbuidos de las relaciones de poder. Por el contrario, sugerimos de modo semejante a Michel Foucault que una genealogía progresiva no lineal

7 Véase Morales, 1994 y 2002.

8 Decimos modernidades en plural, para no depender de un modelo ideal de modernidad universal, a pesar de que resulta todavía irresoluble la herencia hegeliana de las ideas de racionalidad y desarrollo, en las que el museo desempeña un papel importante. Véase Wyss, 1999.

9 Véase Mendiola, 2002: 195-220. 
solo avanza si propicia la resistencia y la transgresión ${ }^{10}$. Y aunque parezca extraño, concebimos al museo como un espacio genuino de la diferencia e idóneo para desarrollar la crítica de sus propios fundamentos modernos.

\section{SALA DE EXPOSICIÓN PERMANENTE: HISTORICIDAD DE LAS OBSERVACIONES}

En consecuencia, cualquier definición de los museos debe considerar el proceso histórico que «los ha situado». Es decir, la mirada museográfica puede «ser observada» espacialmente en el sistema comunicativo social. Como no podemos saber con exactitud qué ocurre dentro de la conciencia del observador (ontología del ser), ni siquiera alcanzamos a detectar la zona erógena de sus ojos (el placer); solo mediante su teatralidad espacial o su manifestación plástica dentro de un campo visual determinado es que la mirada se hace visible colectivamente. Durante los siglos XVI y XVII, los gabinetes de farmacéuticos, botánicos y médicos de la Italia mediterránea ya ofrecían un testimonio preciso de la construcción objetiva acerca del mundo físico, conforme a la visibilidad del empirismo científico ${ }^{11}$. Todo ello desembocó, a principios del siglo XIX, en la invención del espacio museográfico que hizo posible «el punto de vista público». Y con ello, la confrontación racionalista de las miradas donde las obras pictóricas, las esculturas y los bustos observan a sus observadores, al mismo tiempo que son observados. Para comprender el proceso de los museos de México durante el siglo XX, «lo público» no puede darse por sentado porque entraña la cuestión del cómo ha sido administrado ese pasado de la ancestralidad, la memoria histórica y la extrañeza. Sin embargo, en la década de los años setenta del siglo pasado, entró en crisis, en la museología internacional, esa visión racionalista e idealizada del público que visitaba los museos ${ }^{12}$. La cuestión de «lo público» comenzó a ser comprendida con un sentido tan amplio en su pluralidad y diversidad, que surgió la necesidad de replantear la misión de los museos ${ }^{13}$. El museo de la enseñanza objetiva había envejecido. Los clásicos museos de historia, etnografía o arte comenzaron a ser percibidos socialmente como viejos museos de sí mismos.

En México, durante el periodo 1983-2006, los conceptos de lo público y lo privado readquirieron un nuevo sentido en las políticas de museos a partir de:

10 Retomo estas ideas de manera esquemática de las siguientes obras: Foucault, 1984: 76-100 y 32-50; 1998: 175-185.

11 Véase Findlen, 1996.

12 Véase Ames, 1992. Simpson, 1996.

13 Véase un ensayo lúcido sobre el tema, en la visión norteamericana, Weil, 2002: 195-213. 
la crisis de un modelo de gestión social que se sustentaba mediante un alto endeudamiento crediticio exterior; una actividad productiva subsidiada y una renta estatal monopólica de los recursos naturales y energéticos; y la necesidad de reorganización de la política fiscal y los recursos de infraestructura de servicios destinados a la educación y la cultura. Por otra parte, la profunda crisis de legitimidad de la gobernabilidad mexicana - especialmente del periodo 1988-2006 - ha exigido una tibia «devolución» burocrática de la energía social que había sido cooptada a la ciudadanía. Porque los museos ofrecen un servicio a la sociedad, la búsqueda de rentabilidad en los museos no es solo un problema económico, sino fundamentalmente político. Las instituciones culturales y la sociedad, mediante sus profesionales, comunidades científicas, círculos y elites de opinión, replantearon a fines del siglo XX la dimensión del espacio social de la cultura.

\section{SERVICIOS EDUCATIVOS: RENTABILIDAD DE LAS POLÍTICAS DE MUSEOS}

En un marco más amplio, podríamos afirmar que, desde los años sesenta del siglo XX, ocurrió una revolución intelectual sobre una serie de prácticas relacionadas con la conceptuación de «lo público» en el museo ${ }^{14}$. El psicoanálisis freudiano-lacaniano, la sociología cultural y el deconstructivismo científico filosófico, plantearon interrogantes con relación a la zona erógena del ojo, la institucionalización de la comunicación social y el sitio del museo como campo de visión de los gustos canónicos. Tales desarrollos disciplinares produjeron también una nueva discusión sobre la frontera entre lo público y lo privado; entre lo propio y lo extraño; entre identificación y diferencia. En este ambiente, adquirió vigor una nueva discusión en la museología internacional en torno al desarrollo de criterios de planificación y marketing en los programas públicos. En la actualidad disponemos de una literatura especializada, encaminada a la racionalización de la actividad administrativa de los museos ${ }^{15}$. Esto indica, al menos, que estas instituciones dejaron de ser concebidas como almacenes de cosas viejas, puesto que se reconoció, por fin, su importancia en la dinámica cultural de las sociabilidades modernas. A todo ello hay que sumarle la emergencia de una nueva industria cultural en el sector de los servicios, particularmente en el del entretenimiento, lo cual incluye las zonas turís-

14 Solo quiero mencionar dos textos clásicos sobre el tema: Karp, Mullen y Lavine, 1992, y Hooper-Green Hill (ed.), 1994.

15 Una compilación representativa es la de Moore (ed.), 1998. Véase también, Fopp, 1997. Campillo, 1998. VV.AA., 1999. 
ticas y de monumentos histórico-arqueológicos. La internacionalización del entretenimiento cultural acarreó problemas cuando la acción dirigida a la «rememoración del pasado» exigió cada vez mayores incrementos en los subsidios públicos. A los diletantes, escolares y curiosos, se sumaron los turistas, quienes descubrieron en la visita a los museos un tipo de entretenimiento relativamente barato. De esa manera, la museografía contemporánea comenzó a ser incorporada a los enclaves turísticos de la industria cultural. Y la cuestión de la gestión museística adquirió mayor importancia dentro de una economía de mercado que no excluía la participación estatal con fines educativos y sociales.

\section{SALA HIPERTEXTUAL INTERACTIVA: EL ESPACIO MUSEOGRÁFICO COMO ARENA}

Estamos situados, por lo tanto, ante una discusión eminentemente política sobre las modalidades operativas en que puede seguir siendo necesaria la responsabilidad de los gobiernos en la inversión en infraestructura educativa y cultural, así como sobre la normatividad y planeación de los museos públicos. Y esta discusión sobre «lo público» del museo pasa necesariamente por la revisión crítica de los espacios legítimos que le corresponden a la sociedad para hacer uso pleno de su derecho a la cultura, trátese de educación básica y universitaria, del sistema social de salud o de los lugares de la memoria integrados por ruinas y restos arqueológicos precolombinos, monumentos históricos, tumbas y museos. En México, la llegada del tema de la gestión pública en los museos tuvo como contexto histórico el fin de los denominados «estados del bienestar o asistencialistas», ya fuese como exigencia de una reconversión industrial o como consecuencia de estados contables altamente deficitarios, sostenidos por industrias obsoletas y sobreprotegidas. La crítica política del neoliberalismo al nacionalismo populista del periodo 1970-1982, fue implacable. Las grandes reformas sociales del Estado de la Revolución Mexicana (1910-1940) habían decaído cuarenta años después en cascarones vacíos carentes de legitimidad social que la nueva doctrina privatizadora denunció frontalmente. Pero, al mismo tiempo, el neoliberalismo cayó en el desprestigio político (debido a las crisis financieras de 1994-1995 y 2008-2010), lo cual ha terminado paralizando las nociones de progreso, cambio y modernidad. Si la Revolución fue depositada en un Museo Nacional, en 1986, la última modernidad mexicana bien vale un museo de cera. 
En materia de políticas racionalizadoras del gasto público, los años del neoliberalismo acérrimo fueron fructíferos en posturas más democratizadoras de la gestión pública cultural. En el caso del INAH esto es particularmente significativo durante la administración del historiador Enrique Florescano, 1982-1988, caracterizada por una gestión abiertamente reformista y planificadora. Tal postura no era de ninguna manera patrimonio exclusivo del neoliberalismo político. Tenemos un ejemplo contrastante en la década anterior a la hegemonía neoliberal, la del último gran nacionalismo populista mexicano, encabezado por los presidentes Luis Echeverría (1970-1976) y José López Portillo (1976-1982). De hecho, en los años 1972-1976, el INAH, dirigido por el antropólogo Guillermo Bonfil, oficializó en su Política de Museos del $I N A H$, en 1976, una primera crítica frontal al centralismo institucional ${ }^{16}$. Con base en ese documento podemos afirmar que la discusión sobre la gestión y lo público en los museos comenzó con el cuestionamiento, «desde adentro», del aparato cultural del centralismo burocrático de la ciudad de México, con la exigencia del establecimiento de criterios normativos precisos y esquemas organizativos más eficientes. Las políticas culturales del nacionalismo populista intentaron transformar algunos conceptos museológicos, especialmente en lo relativo al elitismo de los museos. La idea de «llevar el museo al pueblo» partía de una revisión exhaustiva de la función social de esas entidades públicas. Al mismo tiempo, hicieron una evaluación positiva de las aportaciones de la tradición museográfica nacionalista, a saber: que la nacionalización de las colecciones desde la era precolombina hasta 1900 (a partir de la Ley Federal de 1972) y la formación de museos nacionales (1944-1965) habían traído como consecuencias ineludibles la secularización y construcción de imágenes de identidad colectiva. Los museos histórico-arqueológicos de México fueron convertidos en templos seculares, lo que significaba reconocer su capacidad para inculcar valores y crear una conciencia cívica. El impacto del robo de las joyas precolombinas del Museo de Antropología, en la Navidad de 1985, hizo patente la sensibilidad social respecto de las instituciones que, en cierto modo, eran modelo de representación museográfica e historiográfica del pasado.

En ese contexto crítico el Programa Nacional de Museos de 1986 cuestionó el atraso en los contenidos histórico-antropológicos, la falta de un sistema nacional que operase como una red desconcentrada en la captación de recursos propios y la completa ausencia de directrices museísticas. Se asumía que la

16 INAH, 1976. 
proliferación de museos respondía a «coyunturas políticas o necesidades inmediatas, ajenas muchas veces a las prioridades de la vida cultural del país ${ }^{17}$. Por último, también se reconocía el divorcio entre las museografías de oropel y las demandas educativas reales de la sociedad. La solución estructural que se propuso fue la creación de un sistema nacional desconcentrado en las capitales estatales de México, cuya toma de decisiones residiría en un Consejo Nacional de Museos. De esta manera, la dirección del INAH abría espacio para una toma colegiada de decisiones, que incorporaba el trabajo técnico y profesional en la planeación, programación, planeación presupuestal, control de gestión y evaluación del área de museos. Este programa se apoyaba en la reforma jurídica de su ley orgánica, aprobada por el congreso legislativo de 1984, donde se vislumbró por primera vez una coherencia de la organización institucional por áreas de trabajo, mediante una toma de decisiones menos vertical y centralizada. El Programa Nacional de Museos de 1986 propuso una puesta al día en la función social del museo, que parecía cooptada por la burocracia. Entre los aspectos que destacaban, en materia de gestión, además de la creación de un Consejo Nacional de Museos, estaba la formulación de «mecanismos de evaluación de los museos como medios de comunicación social, que sirvan también para medir el interés del usuario en ellos» ${ }^{18}$. Asimismo, para apoyar la investigación en materia de museos, se propuso la elaboración «de una revista especializada en museología y museografía» que no solo se ocuparía de los temas locales, sino «también acerca de la situación internacional de los museos» ${ }^{19}$.

Evidentemente, ninguno de los programas citados durante el periodo 1976-1986 tuvo continuidad, a pesar de que todavía en 2006 se siguieron elaborando planes basados en las ideas de esos programas. Es posible que su inviabilidad fuese consecuencia de las resistencias que provocaron en el interior de la propia institución. Cuando se creó el Consejo Nacional para la Cultura y las Artes (CONACULTA), a fines de 1988, el gobierno procuró una salida que fuera lo menos costosa y burocrática. Pero, desafortunadamente, el CONACULTA no despejó «sino incluyó los problemas del INBA y el INAH» ${ }^{20}$. A raíz de la rebelión del Ejército Zapatista de Liberación Nacional (ELZN) en 1994, en el sureste de México, vino una nueva ola de cuestionamientos a esa modernidad transgresora que había situado lo indígena solo en las colecciones museográficas, fuera del conocimiento y de la gestión pública. La antropolo-

17 INAH, 1986: 14.

18 Ibidem, p. 22.

19 Ibidem, p. 24.

20 Tostado, 2003: 19. 
gía oficial y sus escaparates quedaron nuevamente en entredicho, enfrentados a un desgaste de su credibilidad pública. Y las políticas de museos quedaron guardadas en el museo de las políticas.

\section{SALA VIRTUAL: PANORAMA CONTEMPORÁNEO}

En los últimos años ha madurado en México, sin embargo, una «nueva museología» caracterizada por algunas renovaciones en el diseño, los montajes y las temáticas de numerosas exposiciones museográficas $\mathrm{y}$, sobre todo, porque los nuevos proyectos exigen cada vez más una mayor independencia de las prácticas establecidas por la política cultural. Nos referimos a numerosos museos y espacios expositivos de arte contemporáneo y moderno; ciencia y tecnología; historia y antropología ubicados en diferentes partes de la República Mexicana que han diversificado las opciones públicas de esparcimiento y acceso al conocimiento. Al mismo tiempo, la investigación museológica — aquella que se ocupa de una mejor comprensión de los discursos museográficosha desarrollado nuevas perspectivas con énfasis en diferentes campos, como los de: tipo representacional; prácticas de gestión; y recepción estética. El estudio de los museos ha venido a plantear la necesidad de políticas de enseñanza de la historia, del arte y la ciencia, que requieren cada vez más del concurso de investigadores especializados, así como de profesionales de los museos como guías, pedagogos, museógrafos, museólogos, custodios, psicólogos y administradores, entre otros.

Uno de los cambios más importantes en la museología nacional ha sido la cada vez mayor sensibilización sobre el papel crucial que desempeñan los visitantes de los museos. Los museos exigen una interactividad real con sus públi$\cos$, sin los cuales no puede haber una política cultural plenamente democrática. Las colecciones y los visitantes constituyen el alma de cualquier museo. En México, como en muchas otras partes del mundo, la cultura moderna de la visita a los museos arraigó en el transcurso del siglo XX. Si en 1893 había en el país 23 museos que aumentaron a 38 en 190721 , a la fecha se cuenta con 1.250 museos aproximadamente para una población de 113 millones de habi$\operatorname{tantes}^{22}$. Aunque la tendencia mayoritaria sigue mostrando una predominante

21 González Navarro, 1973: 666.

22 Véase la página del sistema de información cultural del CONACULTA: sic.conaculta.gob.mx. A pesar de que sus datos no están actualizados y muchas veces no incorporan otra información sectorial, sirven de referencia general para el objeto de este ensayo. Véase también Witker, 2011. Dicho autor se basa en los datos del CONACULTA y sugiere una crítica del «boom» museográfico de México de las últimas dos décadas. 
responsabilidad estatal se calcula, según fuentes oficiales del CONACULTA, que más de la cuarta parte ya está en manos de diversas asociaciones civiles, organizaciones comunitarias, municipales e instituciones privadas. A pesar de que las fuentes estadísticas tanto oficiales como académicas suelen tener muchas discrepancias entre sí, hay datos incontrovertibles como el que la mayor cantidad de museos se concentra en el Distrito Federal, junto con los estados de México y Jalisco, y hay al menos cuatro museos en las capitales de 30 estados. Debemos tomar en cuenta que muchos de estos museos comparten o coexisten con las zonas arqueológicas, de las que hay más de 170 abiertas al público que, en promedio, reciben casi 10 millones de visitantes al año. En cuanto a monumentos históricos se calcula un universo de 110.424 , estando catalogado hasta ahora un $60 \%$.

Todavía predominan los museos de tipo antropológico e histórico (poco más del 60\%), seguidos de los de arte (menos de una cuarta parte) y los de ciencia (poco más del 10\%). Los museos especializados para niños, por ejemplo, apenas representan el 1\% del total. Por otra parte, además, han surgido nuevas tipologías que incluyen a planetarios, zoológicos, acuarios y reservas naturales que se han incorporado a una concepción más amplia de patrimonio cultural y que rebasa la visión puramente monumentalista que predominó en el siglo XX. Del total de los museos administrados por las instituciones públicas, 135 (un 22\%) dependen de instituciones coordinadas por el gobierno a través del Consejo Nacional para la Cultura y las Artes (CONACULTA): 115 están adscritos al INAH, 17 al INBA, dos al Centro Cultural Tijuana (Baja California Norte) y uno a la Dirección General de Culturas Populares (Museo Nacional de Culturas Populares), en la ciudad de México. Los demás pertenecen a los gobiernos estatales y municipales que son la mayoría ${ }^{23}$.

Estos datos confirman que la divulgación de los valores simbólicos de identidad sigue concentrándose en el área central de México, a pesar de que su divulgación debiera ser una tarea compartida y plural en el resto de la República. Por lo tanto, los problemas de los museos no son únicamente de orden cuantitativo, técnico, administrativo o demográfico. Sí lo son de calidad en sus servicios. Calidad que no puede garantizarse si no hay cuadros calificados, gestión descentralizada y políticas de museos más diversificadas y autónomas. En particular, la situación del norte de México es la que muestra los cambios mayores ya que en esa zona el número de museos aumentó crecientemente desde 1994 con la creación del Museo de Historia Mexicana en Monterrey, Nuevo León. Actualmente se encuentra en la región Norte 390 museos, el 31\%

23 Véase CONACULTA, 2003. INAH, 2001. 
del total, mientras que un 55\% se encuentra situado en el centro y sur del país. Los temas predominantes siguen siendo la antropología, la arqueología y la historia, aunque han proliferado los de arte. El «boom» norteño llama nuestra atención porque carece de una red horizontal que permita coordinar acciones entre sí, evitar duplicación de funciones, gastos en infraestructura y mantenimiento y, sobre todo, que propicie el intercambio de experiencias técnicas, normativas y académicas. Cada uno de esos 390 museos opera conforme a sus límites político-administrativos, así como técnico-financieros. Para llevar a cabo esto se requiere de instancias de planeación museológica que tengan un conocimiento exhaustivo de las demandas educativas y culturales de la sociedad. Ello exige el diseño de modelos de planeación, ejecución, seguimiento y evaluación específicos del campo de los museos.

Por otra parte, a pesar de los avances obtenidos en el crecimiento cuantitativo de la oferta museográfica, hay un rezago lamentable en la formación de profesionales de la museografía, así como de especialistas dedicados a la investigación museológica que propicien una mejor calidad de los servicios de entretenimiento y acceso al conocimiento de los museos. Los organismos oficiales como el Instituto Nacional de Bellas Artes (INBA) y el Instituto Nacional de Antropología e Historia (INAH), han perdido fuerza creativa y permanecen fatalmente determinados por las coyunturas de los periodos presidenciales y las dinámicas de negociación laboral de sus respectivos sindicatos. Como consecuencias negativas de esta situación tenemos la falta de continuidad y coherencia en sus programas y acciones. Ambas instituciones reproducen una museografía ya anticuada, predominantemente elitista y jerárquica en su toma de decisiones.

Así tenemos que, siendo el INAH y el INBA las columnas vertebrales de la museografía y la conservación e investigación de los bienes muebles e inmuebles de la memoria social de México, su consumo cultural ha rebasado las condiciones de infraestructura, gestión y financiamiento con las que fueron creados originalmente entre 1939 y 1947.

Con una población de 113 millones de habitantes y un total de $1.250 \mathrm{mu}-$ seos, hay una proporción de unos 100.000 habitantes por museo. Pero no hay una distribución equilibrada de oferta y demanda porque en los estados de Nayarit, Colima, Veracruz o Tamaulipas encontramos la infraestructura más débil por lo que en esos estados la proporción casi se duplica a unos doscientos mil habitantes por museo ${ }^{24}$. Por el contrario, los museos nacionales de Historia, Antropología y Templo Mayor registran los índices más altos de visitantes

24 Ibidem, 2003: 140-141. 
anuales, de 600.000 a millón y medio en promedio. Este conjunto de museos domina la simbolización de las prácticas científicas y los rituales cívicos de la preservación del pasado remoto de los mexicanos. Pero esta muestra no refleja la situación de escasez crónica de recursos y de marginación que sufren la mayor parte de los museos en la República Mexicana.

\section{SALA DE EXPOSICIONES ALTERNATIVAS: LO PÚBLICO DIVERSO}

Ni el nacional populismo, ni el neoliberalismo se desembarazaron del sistema político centralista ni de la máscara del mestizaje de la homogeneidad étnica. Solo instauraron una nueva retórica, la de la pluralidad cultural ${ }^{25}$, y ante la crónica escasez de recursos económicos, fueron a la búsqueda de nuevos horizontes en diferentes proyectos museográficos. Sin embargo, el paisaje de la gestión pública sigue pareciendo desarticulado, con instituciones que gastan casi todo su presupuesto en el mantenimiento de sí mismas, y cuyas estructuras sindicales resultan ya obsoletas. Por eso ha retornado una discusión tan vieja: la del cumplimiento eficaz con los fines públicos para los que fueron creados los museos. Y para una comprensión cabal de la «diseminación» de las diversidades ${ }^{26}$, se vuelve necesario hacer políticas menos circunscritas a unos territorios específicos y más orientados al diseño de sistemas, redes e interconexiones. Todo el tema de la gestión de los museos parte de la necesidad de diseñar estrategias comunicativas más participativas. No es necesario inventar el hilo negro. Ya se sabe: la importancia histórica del museo permanece asociada a su lugar estratégico en la educación pública, la que siempre exige un cierto equilibrio entre la poética museográfica y la política cultural de las representaciones visuales. El carácter sagrado conferido al origen precolombino de la nación tuvo como consecuencia la creación de espacios mitológicos desde la dominación política. Esa concepción museográfica se convirtió, en el transcurso del siglo XX, en una arena de interlocución entre la hegemonía cultural de la sociedad civil y la coerción de la dominación jurídica del Estado. La creación de museos regionales, locales o comunitarios quedó inscrita en un comportamiento reactivo a ese modelo «nacional» de «hacer-ver la microhistoria $\rangle^{27}$.

25 Véase un ejemplo interesante de esta postura en Bonfil, 1991.

26 Bhabha, 2002: 211-222.

27 Para otros trabajos con propuestas de reformas en la gestión museística, véase Morales, 2000: 35-40; 2001: 202-212; y 2002: 105-120. Un análisis museológico, véase en Morales, 2007: 31-66. 
El modelo nacional revolucionario mexicano de los museos identitarios implantó el rechazo a la heterotopía como un espacio de la diferencia donde confluyen entrelazamientos culturales que son representados, observados y cuestionados. ¿En qué consiste la heterotopía? En que se trata de espacios aislados que yuxtaponen objetos incompatibles con tiempos discontinuos y tienen el rol de crear espacios de ilusión que denuncian al espacio real, inclusive como más ilusorio. ¿Qué hace al museo una heterotopía? La práctica de traer objetos de otros tiempos expuestos en un solo lugar, con la pretensión de ponerlos bajo el resguardo de una idea totalizante del tiempo. Pretende historiarlos dejándolos fuera del tiempo, a la vez que los convierte en documentos, en evidencias específicas de ese otro tiempo discontinuo, de esa temporalidad extraña que es el pasado. La paradoja observada por Beth Lord consiste en ese extraño lugar del museo: es un espacio de tiempo sin tiempo ${ }^{28}$. En síntesis, lo que lo convierte en una heterotopía son tres cosas: su yuxtaposición de objetos en tiempos discontinuos; su intento por presentar la totalidad del tiempo y su aislamiento, como un espacio completo, del tiempo continuo normal. Este efecto de realidad hace aparecer al museo como una aldea sagrada (la de los museos antropológicos o etnográficos) que promete un retorno a una forma de vida cuasi natural «extraviada».

\section{SALA SURREALISTA}

La museografía mexicana ha gozado de prestigio internacional, sin embargo, los recursos invertidos en ella no tomaron en cuenta las necesidades de capacitación profesional y técnica que requiere cada nuevo proyecto. El trabajo de los museos depende del concurso de muchas personas, es una labor que se desenvuelve en equipo y requiere de esquemas de organización bien definidos. La falta de formación de capital humano no ha dado bases firmes para la renovación de modelos de gestión administrativa y técnica, de contenidos y prácticas museográficas que sean sustentables a largo plazo. El Instituto Nacional de Bellas Artes (INBA) y el Instituto Nacional de Antropología e Historia (INAH), los gobiernos de los estados y algunas universidades han realizado actividades de docencia en las artes plásticas y escénicas, así como de conservación del patrimonio artístico e histórico-arqueológico, que han resultado insuficientes para satisfacer la demanda que hay en los más de mil museos de México. Los programas para la formación de profesionales de los mu-

28 Lord, 2006: 11-14. 
seos (museógrafos, directivos, investigadores) que el INAH ha impulsado, a través de la Escuela Nacional de Conservación Restauración y Museografía (ENCRyM), a nivel de posgrado, son de reciente creación y no operan ni desarrollan todavía cuerpos académicos, ni siquiera redes de enlace con los museos públicos de México, ni tampoco con el resto del mundo. Muy recientemente otras universidades como la Universidad del Claustro Sor Juana, la Universidad Autónoma de la Ciudad de México y el Instituto de Investigaciones Dr. José M. ${ }^{a}$ Luis Mora han comenzado a desarrollar licenciaturas, especializaciones o posgrados ya sea en museos o en conservación y divulgación del patrimonio cultural, pero aún es muy temprano para evaluar su impacto real en el ámbito museográfico y artístico.

El caso del INBA es particularmente dramático porque posee un sistema académico de proporciones universitarias, tanto en lo cualitativo (pues brinda educación en los niveles medio, medio superior y superior, así como también desarrolla tareas de investigación), como en lo cuantitativo - más de 30 institutos entre escuelas de todos los niveles y los centros nacionales de investigación, con una población de 9.000 alumnos y 2.000 académicos, aunque tiene solo 196 investigadores $^{29}$. A pesar de su magnitud, sin igual en el resto de México y América Latina, carece de un presupuesto razonable que le permita un mejor desempeño y desarrollo de su potencial artístico, docente y científico. Pese a la vinculación «orgánica» del INBA con el CONACULTA o la Secretaría de Educación Pública, la situación de los académicos difiere en muchos aspectos sustantivos de los de otras instancias (como el INAH u otros sistemas universitarios apoyados por el Estado). Sin ir más lejos, la Secretaría de Educación Pública tiene mecanismos de estímulos a académicos y financiamiento a instituciones a los que el INBA no tiene acceso por deficiencias normativas y por una concepción predominantemente burocrática de la promoción cultural. Tampoco hay acuerdos con el Sistema Nacional de Investigadores ni con el CONACYT para que los académicos accedan a sus beneficios. A pesar del trabajo realizado en los Centros Nacionales de Investigación, Documentación e Información de ese Instituto, no existe todavía una política consistente y sólida de adquisición, preservación e informatización de la misma, ni espacio físico para cumplir tal misión. Actualmente ni el Centro Nacional de Investigación, Documentación e Información en Artes Plásticas (CENIDIAP), ni la Biblioteca del Centro Nacional de las Artes, pueden recibir ni siquiera donaciones, de manera que la formación de colecciones de archivos se ha visto detenida, por no decir abandonada ${ }^{30}$.

29 Schmilchuk, 2006.

30 Idem. 
De cualquier modo, las principales iniciativas de formación de profesionales se siguen concentrando en la ciudad de México lo que refuerza la tendencia histórica del siglo XX: la centralización de la política cultural en detrimento del desarrollo regional y la pluralidad étnica y cultural del país. El éxito de la museografía mexicana sigue reposando en el empirismo, buen gusto y talento de diseñadores, artistas, curadores y directivos.

Ciudades como Oaxaca, Puebla, Morelia, Cuernavaca, San Cristóbal Las Casas, Zacatecas, Guadalajara, Veracruz, Mérida, Chetumal, Monterrey, Saltillo y Chihuahua necesitan con urgencia del concurso de la sociedad para responder con éxito a la problemática de la expansión del llamado turismo cultural y ecológico, así como de las empresas del entretenimiento. Los afanes centralistas y coyunturales de continuar creando museos y exposiciones por doquier deben procurar la creación de proyectos sustentables a largo plazo y ocuparse de manera responsable de los ya existentes con la participación de programas integrales de fortalecimiento institucional, así como de la participación transparente de las organizaciones sociales y civiles.

\section{DivÁN MUSEOLÓGICO}

A comienzos del siglo XXI, México sigue adaptando a sus propias condiciones históricas el ideario progresista de la modernización mediante un proceso que pasa por las hegemonías educativas y la reproducción simbólica de la sociedad. Si observamos con atención sus referentes imaginarios, México mantiene una gran autonomía cultural en sus modos de avizorar el futuro. Esto se debe a una fuerte presencia del pasado en la vida de los mexicanos. Porque preservan con orgullo su pasado y sus valores estéticos en ruinas arqueológicas, museos, monumentos históricos y artísticos, probablemente sea lo único sobre lo que los mexicanos tienen certeza. Instituciones como los museos vinieron a concretar el concepto abstracto de mexicanidad. Los héroes nacionales, las grandes luchas sociales, los genios artísticos y las grandes construcciones arquitectónicas han hecho que México tenga en el Castillo de Chapultepec, en Monte Albán, en los murales del Palacio Nacional y el ex-colegio de San Ildefonso, en el ex-convento de Churubusco y el ex-colegio de Tepotzotlán, Templo Mayor y Teotihuacan, entre muchos otros ejemplos, los grandes símbolos de su unión. A los que habrá que sumar las numerosas y variadas aportaciones ocurridas en el transcurso del siglo XX, lo mismo en la industria y la tecnología que en las artes escénicas y plásticas, así como en la arquitectura, la música, el cine, el teatro y la literatura. 
Desde 1976 se han incrementado los debates en relación a cómo mejorar la distribución de los recursos y la calidad de la tarea que desempeñan los museos. ¿Por qué tendría el Estado que preocuparse por la cultura? Porque es indispensable la elaboración de estrategias de persuasión, transmisión y comunicación mediáticas que coadyuven a nuclear consensos y acciones. Esto no es nuevo en México puesto que hay indicios de una tradición política en la que la cultura ha quedado siempre en la órbita de los intereses del Estado. En el siglo XIX formó parte del proyecto secularizador del liberalismo y en el siglo XX aparece vinculado a proyectos de modernización económica y social además de contribuir a la consolidación de los valores de identidad del nacionalismo revolucionario.

Es innegable que uno de los debates más álgidos consiste en las modalidades para convertir al Estado en menos protagonista y más garante de una rectoría normativa y técnica. Se ha considerado en distintos foros y estudios que su ejercicio debiera limitarse a una gestión descentralizada y desconcentrada de las iniciativas sociales en materia de protección y difusión del patrimonio histórico y cultural. Para evitar el gigantismo burocrático que ha propiciado el dirigismo cultural el gobierno debe diseñar prácticas que propicien la «corresponsabilidad» con la sociedad civil (organizaciones sociales, iniciativa privada, particulares, etcétera) y la sociedad política (los partidos políticos, las ONG, por ejemplo).

Mediante una regulación normativa rectora por parte del Estado, la iniciativa privada, como cualquier otro actor político proveniente de la sociedad puede desempeñar un papel sumamente creativo en la conservación y difusión del patrimonio. Lejos de inhibir la capacidad creativa de la sociedad debe promoverse, por el contrario, una participación responsable a través de fideicomisos, patronatos, asociaciones civiles en las que hombres de negocios y pequeños propietarios, intelectuales o grupos políticos asuman su responsabilidad en la conservación del patrimonio histórico de México. Los conflictos entre ciudadanía y sociedad política provienen de aquellos espacios donde el Estado-Nación impuso un modelo no democrático de incorporación a la modernidad sin respetar los moldes tradicionales. La nueva secularización del siglo XXI apunta claramente hacia la recuperación de espacios de autonomía ciudadana de la burocracia cultural. Esto significa construir consensos y redes con propuestas viables que apunten a la organización solidaria de la sociedad civil. Quedan fuera de este horizonte las salvaciones autoritarias, aquellas en las que solo se hace responsable de los problemas de la cultura a una minoría iluminada de intelectuales o a la omnipresencia de las instancias gubernamentales. La transición obligada de la nueva museología a una era de mayor participación social consistirá en mantener políticas culturales y educativas que contribuyan a una 
planeación más democrática, plural y eficiente de los museos y los espacios expositivos de México, así como un papel creativo en el fortalecimiento de la autonomía de la sociedad de los intereses corporativos creados por el aparato cultural en la segunda mitad del siglo XX.

En conclusión, el género de los museos de historia y arqueología no consiste únicamente en la puesta en escena del pasado, sino sobre todo en su interpretación. De ahí que los museos de historia sean también museos de sí mismos, y solo mediante «desmontajes» hermenéuticos podemos desentrañar los diferentes niveles de verdad y ficción (verdad historiográfica y verdad museográfica) involucrados en las exhibiciones. Situar las comprensiones históricas es una operación distinta a la de ver empíricamente (a través de vitrinas) la realidad (los objetos) de los hechos históricos (los referentes) ${ }^{31}$.

Irónicamente, en la tierra del «Benemérito de Las Américas» Benito Juárez, en Oaxaca, están operando desde hace muchos años prácticas diferentes de apropiación civil de los contenidos de los museos arqueológicos, históricos y etnográficos. En 1986-1988, en los valles centrales zapotecos fueron construidos dos museos comunitarios en Santa Ana del Valle, Tlacolula, Oaxaca, y San José «El Mogote», Etla, Oaxaca, en un contexto crítico de la museología mexicana que propugnaba por alguna democratización del museo público ${ }^{32}$. Una característica singular de estos primeros museos comunitarios (actualmente son más de 15 y comprenden también regiones mixtecas) es que omitían la exposición de los periodos colonial y del siglo XIX. Juárez no aparece en ninguna parte. Es una ausencia, una omisión que llama la atención. Las salas museográficas mantienen relaciones comunicativas del presente inmediato al pasado ancestral. No hay algo que se denomine «historia moderna».

A fines del siglo XX, los museos comunitarios oaxaqueños muestran cómo la representación etnográfico-arqueológica puede retornar a sus legítimos poseedores. Los objetos permanecen en su lugar de origen - sin necesidad de «importar» colecciones del Museo Nacional de Historia, ni mucho menos del Museo Nacional de Antropología - mediante la transfiguración que se da del

31 La hermenéutica: «(...) acaba siendo no solo una función propedéutica de toda historiografía - como el arte de la interpretación correcta de las fuentes escritas - sino que abarca en realidad todo el negocio de la historiografía. Pues lo que se afirma de las fuentes escritas, que en ellas cada frase no puede entenderse más que desde su contexto, vale también para los contenidos sobre los que dan noticia. Tampoco el significado de éstos está fijo en sí mismo. (...) El verdadero objeto histórico no es un objeto, sino que es la unidad de lo uno y del otro, una relación en la que la realidad de la historia persiste igual que la realidad del comprender histórico. Una hermenéutica adecuada debe mostrar en la comprensión misma la realidad de la historia. (...)». Gadamer, 1991: 229 y 370.

32 Para un análisis pormenorizado de los años 1986-1994, Morales, 1995: 13-44. 
contexto museográfico a la comunidad cultural. La noción de comunidad ayuda al museo a concentrar el interés común de diferentes grupos sociales dentro de su área, haciendo posible un amplio espectro de patrones culturales que emanan de esos mismos grupos. La ruptura en las prácticas de gestión de los museos comunitarios no los liberó por completo de la «huella moderna». Comparten en su imaginario la tesis del nacionalismo liberal de fincar en el pasado prehispánico el origen de la identidad colectiva. Los museos tampoco han surgido sobre las ruinas de algún inmueble religioso. Simplemente, las historias que narran no coinciden con las acostumbradas periodizaciones de los historiadores oficiales.

En un estudio reciente, la curadora de arte y museóloga estadounidense, Selma Holo, concluyó que este tipo de museos eran de vanguardia y contemporáneos a otras experiencias semejantes desarrolladas en Estados Unidos, Inglaterra o Francia ${ }^{33}$. El hecho de que la toma de decisiones en los museos comunitarios radica en asambleas pueblerinas, en los viejos usos y costumbres de las comunidades rurales, contraviene por completo la «tradición juarista» de la modernidad mexicana. Si queremos sacar de la vitrina al Juárez de carne y hueso debemos voltear a mirar las prácticas ciudadanas de apropiación de su propia historia. Oaxaca se anticipó a los cambios de los nuevos paradigmas comunicativos y sociales de los museos pero lo hizo recuperando una vieja costumbre, anti-liberal por cierto: la de las formas tradicionales de gobierno (como los sistemas de cargo) y ciertas formas del trabajo coercitivo (como el tequio) de los pueblos campesinos. Además, en sus etnografías expositivas se muestran las adaptaciones realizadas a la liturgia católica en sincretismos propios del siglo XX. ¿Por qué Oaxaca resulta importante para estudiar el ambiente cultural de México? Porque reúne cualidades como espacio de encrucijada de los grandes dilemas. Oaxaca tiene algo de todo México: «Quizá Oaxaca mantiene una relación periférica respecto de la ciudad de México, pero no es provinciana. Ahí la gente siempre está viajando, trayendo nuevas ideas y cada vez más sus artistas van por todas partes absorbiendo nuevas ideas para sí mismos. No es casual que a pesar de ser uno de los estados más pobres de la República mexicana, Oaxaca siempre ha jugado un papel crucial en los dramas políticos y culturales de la Nación $\rangle^{34}$.

Para muestra ahí están los botones: Benito El Benemérito, Porfirio Díaz, el dictador republicano, José Vasconcelos (La raza cósmica), Rufino Tamayo, Rodolfo Morales, Eduardo Mata, Francisco Toledo y Lila Downs, entre mu-

33 Holo, 2004.

34 Traducción del autor, en Holo, 2004: 13. 
chos otros. Holo escogió al laboratorio oaxaqueño porque ha estado involucrado en las memorias cruciales de la historia nacional, porque se mueve entre la injusticia y las grandes aportaciones. En el contexto de los bicentenarios conmemorativos se hace necesario emprender otra construcción (desamortización) secular del nacionalismo político de México; ya no en manos del monopolio estatal sino de la diversidad cultural e ideológica de la sociedad civil. Actualmente, en México se calcula que hay unos 90 museos comunitarios, no todos con raíz indígena pero sí imbuidos de una praxis menos vertical que la que heredaron de la «museopatria» y las políticas culturales del México posrevolucionario. En Centroamérica hay unos 12, y en América del Sur, 22, y todos ellos se organizan a través de la Red de Museos Comunitarios de América. En sentido estricto, no se trata de museos propiamente dichos. Son en realidad pequeños montajes, espacios expositivos modestos, ubicados muchas veces en zonas de alta marginalidad social y que no han desarrollado todavía cuadros profesionales técnicos capaces de impulsar una museología subalterna.

Así vemos que desde la celebración de los «centenarios» de la independencia de España, en 1910, especialmente en el caso mexicano, se construyó una «museopatria» que ha condensado un saber, una praxis y un espacio canónicos de la representación histórica. El estudio museológico de las conmemoraciones es importante por eso. No tanto porque ofrezcan datos político-culturales sino porque, como ha escrito recientemente el historiador Tomás Pérez Vejo, ofrecen huellas de los procesos de construcción nacional en Hispanoamérica, posiblemente uno de los más exitosos del siglo XX (en comparación con África o, inclusive, Asia). Y los museos histórico-arqueológicos jugaron un rol crucial en la consolidación del mundo empírico del ser nacional y la ontología de la identidad. Es aquí donde encontramos la doble faceta de los museos históricos y casi de cualquier otro tipo de museos: la relación entre fenómenos perceptivos de los procesos empíricos y las elaboraciones de sentido. En los museos de historia se guardan no únicamente objetos o colecciones, sino reliquias, monumentos, emblemas, símbolos. Se mueven no únicamente en la esfera del conocimiento, sino también en el mundo de lo sensible, lo afectivo, de las emociones políticas. Los nacionalismos culturales a los que pertenecen esos museos tanto nacionales como comunitarios es algo que puede ser pensado desde la construcción de una forma de la representación política de la historia. Se trata de historia pública «desde abajo». 


\section{REFERENCIAS BIBLIOGRÁFICAS}

Ames, Michael M., Cannibal Tours and Glass Boxes: the Anthropology of Museums, Canadá, University of British Columbia Press, 1992.

Bhabha, Homi K., «Narrando la nación», Álvaro Fernández Bravo (comp.), La invención de la nación. Lecturas de la identidad de Herder a Homi Bhabha, Buenos Aires, Manantial, 2002: 211-222.

Bonfil, Guillermo, Pensar nuestra cultura, México, Alianza Editorial, 1991.

Bur, Claudia, Juárez con la República bajo el brazo, México, Ediciones Tecolote, 2005.

Campillo, Rosa, La gestión y el gestor del patrimonio cultural, Murcia, Editorial KR, 1998.

CONACULTA, Atlas de infraestructura cultural de México, México, Consejo Nacional para la Cultura y las Artes, 2003.

Findlen, Paula, Possessing Nature. Museums, collecting, and scientific culture in Early Modern Italy, Berkeley y Los Ángeles, University of California Press, 1996.

Fopp, Michael, A., Managing Museums and Galleries, Londres, Routledge, 1997.

Foucault, Michel, «Nietzsche, Genealogy, History», Paul Rabinow (ed.), The Foucault Reader, Nueva York, Pantheon, 1984a: 76-100.

Foucault, Michel, «What is Enlightenment?», Paul Rabinow (ed.), The Foucault Reader, Nueva York, Pantheon, 1984b: 32-50.

Foucault, Michel, «Different Spaces», Michel Foucault, Essential Works of Foucault 1954-1984, Vol. 2, Londres, Penguin, 1998: 175-185.

Gadamer, Hans-George, Verdad y método, Salamanca, Ediciones Sígueme, 1991: 229-370.

González Navarro, Moisés, «Instrucción Pública», Daniel Cosío Villegas (coord.), Historia Moderna de México, IV, El porfiriato, vida social, México, Editorial Hermes, 1973: 520-690.

Grüner, Eduardo, El sitio de la mirada. Secretos de la imagen y silencios del arte, Buenos Aires, Grupo Editorial Norma, 2001.

Holo, Selma, Oaxaca at the crossroads, managing memory, negotiating change, Washington, Smithsonian Books, 2004.

Hooper-Green Hill, Eilean (ed.), The Educational Role of the Museum, Londres, Routledge, 1994.

INAH, Política de Museos del INAH, México, Instituto Nacional de Antropología e Historia, 1976. 
INAH, Programa Nacional de Museos, Instituto Nacional de Antropología e Historia, México, 1986.

INAH, Lineamientos generales de trabajo para museos 2001/2006, México, Coordinación Nacional de Museos y Exposiciones del INAH, 2001.

Karp, Ivan; Mullen, Christine; y Lavine, Steven D., Museums and communities. The Politics of Public Culture, Washington, Smithsonian Institution Press, 1992.

Lord, Beth, «Foucault's museum: difference, representation, and genealogy», $\mathrm{Mu}$ seum and Society, IV/1 (Leicester, 2006): 11-14.

Mendiola, Alfonso, «Entrevista a Han Ulrich Gumbrecht: la fascinación por el pasado», Historia y grafía, 18 (México, 2002): 195-220.

Moore, Kevin, (ed.), La gestión del museo, Gijón, Ediciones TREA, 1998.

Morales, Luis Gerardo, «Museopatria revolucionaria», Memoria del Congreso Internacional sobre la Revolución Mexicana, tomo I, México, Gobierno del Estado de San Luis Potosí, Instituto Nacional de Estudios de Históricos de la Revolución Mexicana, 1991: 398-411.

Morales, Luis Gerardo, Orígenes de la museología mexicana. Fuentes para el estudio histórico del Museo Nacional, 1780-1940, México, Universidad Iberoamericana, 1994.

Morales, Luis Gerardo, «Los espejos transfigurados de Oaxaca», Boletín Archivo General de la Nación, 3 (México, 1995): 13-44.

Morales, Luis Gerardo, «La nueva museología mexicana», Revista de Museología, 20 (Madrid, 2000): 35-40.

Morales, Luis Gerardo, «El objeto museográfico y las políticas del signo icónico», Primeras Jornadas de Patrimonio Intangible «Memorias, identidades e imaginarios sociales» (Buenos Aires, 2001): 202-212.

Morales, Luis Gerardo, «Desafíos de la museología contemporánea: La “desovietización” museográfica de México», Mónica Lacarrieu y Marcelo Álvarez (comps.), La (indi)gestión cultural. Una cartografía de los procesos culturales contemporáneos, Buenos Aires, Ediciones CICCUS / La Crujía, 2002a: 105-120.

Morales, Luis Gerardo, «Objetos monumento y memoria museográfica a fines del siglo XIX en México», Historia y grafía, 18 (México, 2002b): 63-98.

Morales, Luis Gerardo, «Museológicas. Problemas y vertientes de Investigación en México», Relaciones, XXVIII/111, (Zamora, 2007): 31-66.

O’Gorman, Edmundo, México, el trauma de su historia. Ducit amor patriae, México, Universidad Nacional Autónoma de México, 1977.

Schmilchuk, Graciela, «Notas para un diagnóstico de la investigación artística y algo más», con la colaboración de Carlos Guevara y Francisco Reyes Palma, CENIDIAP, 2006. Versión electrónica. 
Simpson, Moira G., Making Representations. Museums in the Post-Colonial Era, Londres y Nueva York, Routledge, 1996.

Tostado, Conrado, «Voltear a ver», Letras Libres, 50 (México, 2003): 18-22.

VV.AA., Lo público y lo privado en la gestión de museos. Alternativas institucionales para la gestión de museos, Buenos Aires, Fondo de Cultura Económica, 1999.

Weil, Stephen E., «The Museum and the Public», Stephen E. Weil (ed.), Making Museums Matter, Washington, Smithsonian Institution Press, 2002: 195-213.

Witker, Rodrigo, «Museografía mexicana contemporánea», Ponencia inédita presentada en el Seminario Permanente de Museología de América Latina, Escuela Nacional de Conservación, Restauración y Museografía del INAH, 26 de octubre de 2011.

Wyss, Beat, Hegel's Art History and the Critique of Modernity, Nueva York, Cambridge University Press, 1999.

Zermeño, Guillermo, La cultura moderna de la historia. Una aproximación teórica e historiográfica, México, El Colegio de México, 2002: 41-146.

Fecha de recepción: 13 de septiembre de 2011.

Fecha de aceptación: 22 de diciembre de 2011.

\section{Subaltern museology (on the ruins of Moctezuma the $2^{\text {nd }}$ )}

«Subaltern museology» combines the historian's gaze with the ambit of museographical observations with the intention of bringing to the reader a synthesis of the museums that exist in Mexico. We carry out historical museography because our aim is to "historicize» the different modernities of sociability and the public gaze in extra-European territories. We have opted for a critical position in relation to the European hegemonies which produced the invention of museographical observation through diversified designs, architectures, technologies and educational and social ideas. In this way, we understand the museum as a space of difference and representation, which allows for a genealogical conception of discontinuity. The European transfer of museum culture to America was not a mere reproduction but recreated genuine patterns and practices. That is why we call our essay «subaltern museology», because there are postcolonial countries with significant representations such as the creation of a modern culture of ancestry which, in the case of Mexico, promoted the formation of a nation-state of great symbolic legitimacy.

KEY WORDS: subaltern museology; difference, representation; discontinuity; different modernities; immanent consciousness; transcendent consciousness; museum-fatherland. 